\title{
Fuzzy Logic for Rainfall-Runoff Modelling Considering Soil Moisture
}

\author{
Gokmen Tayfur $^{1} \cdot$ Luca Brocca $^{2}$
}

Received: 24 November 2014 / Accepted: 17 April 2015 /

Published online: 8 May 2015

(C) Springer Science+Business Media Dordrecht 2015

\begin{abstract}
This study developed Mamdani-type fuzzy logic model to simulate daily discharge as a function of soil moisture measured at three different depths (10, 20 and $40 \mathrm{~cm}$ ) and rainfall. The model was applied to $13 \mathrm{~km}^{2}$ size Colorso Basin in central Italy for a period from October 2002 to April 2004. For each variable of soil moisture, rainfall, and discharge, 9 fuzzy subsets were employed while 30 fuzzy rules, relating the input variables (soil moisture and rainfall) to the output variable (discharge), were optimized. The model employed the min inferencing, max composition, and the centroid method. The model application results revealed that Mamdani-type fuzzy logic model can be employed to incorporate soil moisture along with rainfall to simulate discharge. Using soil moisture measured at $40 \mathrm{~cm}$ soil depth along with rainfall produced better simulation of discharge with $N \boldsymbol{S}=\mathbf{0 . 6 8}$ and $R=$ 0.82. The performance of the model was also tested against a conceptual rainfallrunoff model of MISDc (Modello Idrologico Semi-Distribuito in continuo). MISDc couples an event-specific component with a module for continuous time soil water balance for taking into account the variable antecedent wetness conditions. The MISDc model requires estimation of seven parameters and the measurements of the hydrometeorological variables such as rainfall and air temperature. The comparative study revealed that fuzzy model performs better in capturing runoff peak rates and overall trend of high and small flooding events.
\end{abstract}

Keywords Soil moisture $\cdot$ Rainfall $\cdot$ Discharge $\cdot$ Simulation $\cdot$ Fuzzy logic $\cdot$ Mamdani $\cdot$ Watershed

Gokmen Tayfur

gokmentayfur@iyte.edu.tr

Luca Brocca

luca.brocca@irpi.cnr.it

1 Department of Civil Engineering, Izmir Institute of Technology, Urla, Izmir, Turkey

2 Research Institute for Geo-Hydrological Protection, CNR, Perugia, Italy 


\section{Introduction}

The importance of soil moisture on runoff, infiltration, and evapotranspiration is well known in the literature (Goodrich et al. 2004; Merz and Plate 1997; Scipal et al. 2008; Brocca et al. 2009a). Specific monitoring programs (Merz and Bardossy 1998; Aubert et al. 2003; Morbidelli et al. 2012) and modelling studies (Gautam et al. 2000; Anctil et al. 2004; Casper et al. 2007; Komma et al. 2008; Berthet et al. 2009; Brocca et al. 2012b; van Steenbergen and Willems 2013) were carried out to investigate the influence of soil moisture on runoff hydrographs.

Many studies investigated the use of soil moisture in Rainfall-Runoff (RR) models. Preliminary applications considered soil moisture data for the improvement of the calibration and verification of RR models (Wooldridge et al. 2003, Koren et al. 2008, Parajka et al. 2009). Some studies directly used the soil moisture observations for the assessment of the antecedent wetness conditions through in-situ (Meyles et al. 2003; Huang et al. 2007; Zehe et al. 2010) and remotely sensed (Jacobs et al. 2003; Brocca et al. 2009b; Beck et al. 2010) estimates. Goodrich et al. (2004)) pointed out that, when the spatial-temporal variability of rainfall is known, basin-wide remotely sensed average initial soil moisture can be sufficient for RR modelling in semiarid regions. Brocca et al. (2009a) stated that the integration of in situ soil moisture observations into a simple event-based RR model can improve the runoff hydrographs predictions. Grayson and Western (1998) suggested that a network of a limited number of soil moisture sensors can provide reliable estimates of areal mean soil moisture time series data that can potentially be used as antecedent conditions. All these studies suggest that in situ soil moisture data from few numbers of locations can provide useful information for runoff predictions at the basin scale.

Although some studies employed artificial intelligence techniques (or data driven techniques) for modelling the RR process (Elshorbagy et al. 2010), only few of them attempted to use (modelled or observed) soil moisture data for runoff predictions. Gautam et al. (2000) employed the back propagation Artificial Neural Network (ANN) to predict runoff using only soil moisture data measured at 20 and $40 \mathrm{~cm}$, without rainfall, in Tono catchment in Japan $\left(0.52 \mathrm{~km}^{2}\right)$. Tono catchment has steep slopes and it is located in a humid region with very low evaporation rates where most of the time the soil is close to saturation (Gautam et al. 2000). The results of the ANN model showed good agreement with the measurements and it was found that the $40-\mathrm{cm}$ soil moisture provides the most important information for runoff estimation. Anctil et al. (2004) employed soil moisture data from a river catchment (Seine River near Paris) that drains $1949 \mathrm{~km}^{2}$ area with a travel time of about 3 days. They used daily values of discharge, soil moisture index (obtained from a continuous RR model), rainfall and potential evaporation in the input vector of ANN model to predict runoff. The use of the soil moisture index as an additional input in ANN resulted in increased simulation skills. Anctil et al. (2008) used a similar dataset from a $104 \mathbf{~ k m}^{\mathbf{2}}$ catchment in France for forecasting daily flow rates, but employing in situ soil moisture observations at 5, 35 and $95 \mathrm{~cm}$ depth. In their study, the major improvements were obtained by using soil moisture data at $35 \mathrm{~cm}$ depth. The major disadvantage of ANN is that it is a black box model which does not reveal any insight in understanding the underlying physical process.

Casper et al. (2007) were the first that developed a fuzzy logic based rainfall-runoff model using soil moisture measurements to represent system state. They employed Takagi-SugenoKang (T-S-K) approach where the antecedent part of the fuzzy IF-THEN rules are expressed verbally while the consequent part consists of mathematical expression (Takagi and Sugeno 
1985). The antecedent part of the constructed 36 rules involved only soil moisture information while the consequent part mathematically computed discharge (Casper et al. 2007). Since such T-S-K fuzzy model involves mathematical expressions, it requires an extra work of the estimation of the model parameters, which is often a difficult task. Moreover, significant uncertainties affect soil moisture and precipitation data, due to measurement errors and spatial representativeness (Brocca et al. 2012a), as well as discharge data (Di Baldassarre and Montanari 2010). Hence, it may be more appropriate to employ Mamdani-type fuzzy model where not only antecedent but also consequent parts of IF-THEN rules are all expressed verbally. This approach is also more advantageous since it avoids the parameter estimation problem.

On this basis, this study developed Mamdani-type fuzzy model which uses, as input variables, not only soil moisture but also precipitation in the antecedent parts of the rules. Indeed, soil moisture and precipitation are expected to be the two most important variables for the estimation of runoff. The model is applied to $13 \mathrm{~km}^{2}$ sized catchment in central Italy (Colorso) where the Mediterranean climate is dominant; a period from October 2002 to April 2004 is used for the analysis. Moreover, the Mamdani-type fuzzy model results are compared with a classical continuous rainfall-runoff model, named MISDc ("Modello Idrologico Semi Distribuito in continuo", Brocca et al. 2011), for assessing the benefits and limitations related to the simulation of the rainfall-runoff process with a fuzzy type modelling approach.

To our knowledge, this study is the first one employing Mamdani-type fuzzy logic model using moisture and rainfall as input variables to predict daily runoff rates. It used extended time period soil moisture measurements at three different soil depths. It carried out comparison against a conceptual rainfall-runoff model to assess the reliability of the results. Mamdani-type fuzzy model operates with fuzzy sets and IF-THEN fuzzy rules that involve neither mathematical expressions nor numerical simulations. It does not require parameter estimation, which is a major problem in hydrologic modelling.

\section{Experimental Catchment and Dataset}

The Colorso stream is a tributary of the Niccone stream, which a subcatchment of the Tiber River Basin in central Italy. The catchment has an area of $13 \mathrm{~km}^{2}$ at Pian di Marte river section (see Fig. 1). The Colorso catchment is characterized by the Mediterranean climate with precipitation mostly in the autumn-spring period, when floods generally occur. Based on the period 1989-2012, the average annual precipitation was about $870 \mathrm{~mm}$ homogeneously distributed on the whole catchment. The maximum mean monthly precipitation occurs in November (on average $125 \mathrm{~mm}$ ) and the minimum in July $(32 \mathrm{~mm}$ ). The peak runoff occurs in the period between December and April. In the summer period, the minimum and maximum monthly temperature values, on average, are 13.5 and $22.5{ }^{\circ} \mathrm{C}$, respectively; whereas in the winter period they are 4.0 and $10.5^{\circ} \mathrm{C}$, respectively.

The catchment lithology is mainly characterized by layered sandstones interleaved with thin marls and pelitic levels ( $72.8 \%$ ), second by clays with chaotic structure (15.0\%) and third by alluvial deposits constituted by gravel and sand $(11.7 \%)$.

The experimental soil moisture data set selected for this study covers the period from October 2002 to April 2004. Soil moisture was monitored at depths of 10, 20, and $40 \mathrm{~cm}$ with six continuous Frequency Domain Reflectometry (FDR) sensors (Sentek Sensor Technologies 


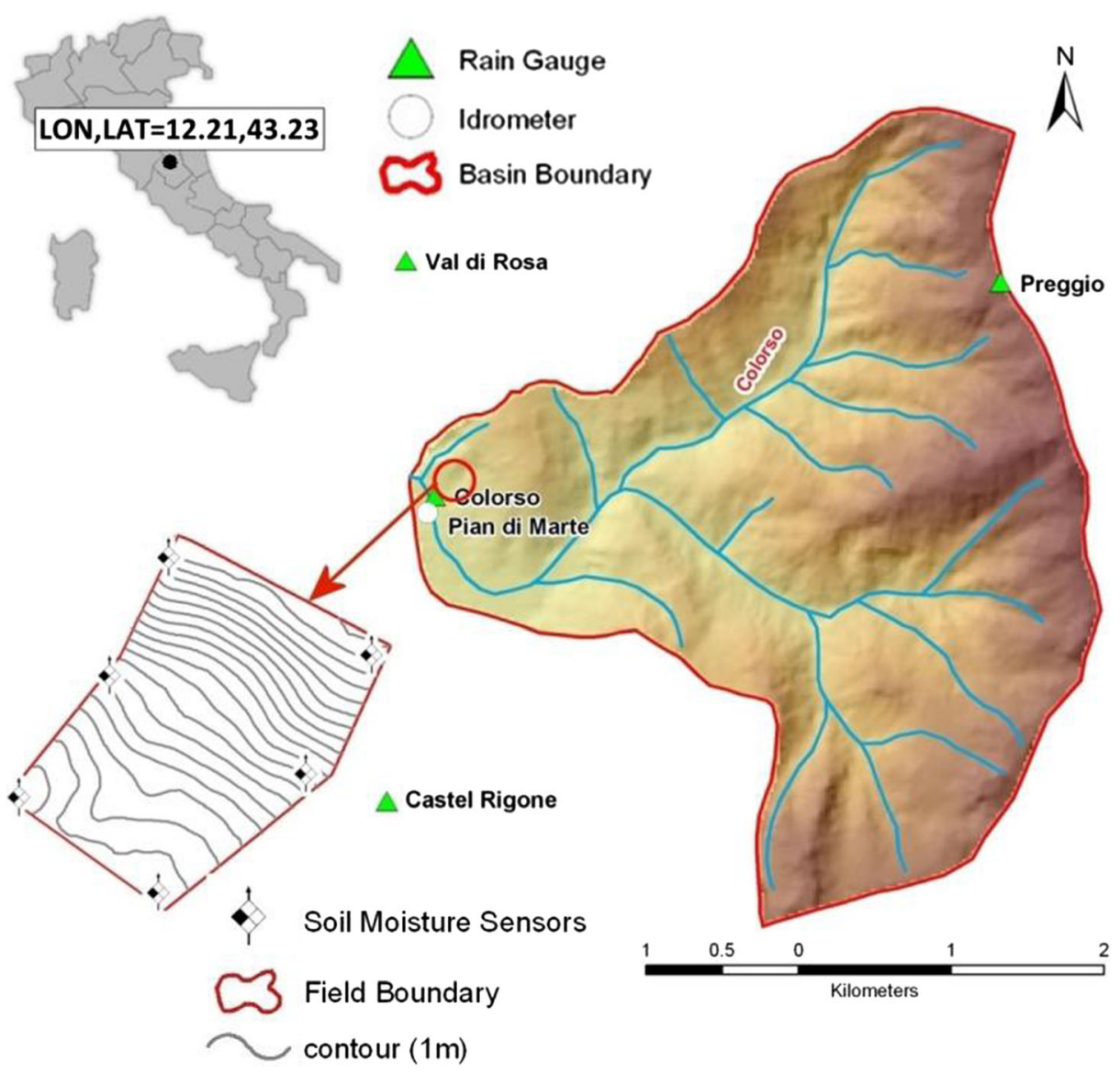

Fig. 1 Topography of the Colorso catchment with the location of the meteorological and soil moisture stations. The longitude (LON) and latitude (LAT) coordinates of the catchment centroid are shown

1997) located in an experimental plot of 1 ha (see Fig. 1). The average of the six sensors at different depths is used as 'observed' soil moisture data here in after. Rainfall is measured by four raingauge stations located within (or close to) the catchment while the water level, converted in flow discharge through a reliable rating curve, is continuously monitored at the outlet (see Fig. 1). Figure 2 shows temporal variation of measured soil moisture data, along with precipitation and discharge for the Colorso catchment. As it can be seen, soil moisture at $10 \mathrm{~cm}$ depth shows a rapid rise during heavy rainfall, followed by a recession which differs according to the period of the year and to the meteorological conditions. The sensors at 20 and $40 \mathrm{~cm}$ depth show a delayed response to rainfall and also saturated conditions during very wet periods.

\section{Mamdani Fuzzy Logic Model}

Fuzzy logic has been employed in water resources engineering area such as reservoir operation modelling (Panigrahi and Mujumdar 2000), sediment transport prediction 


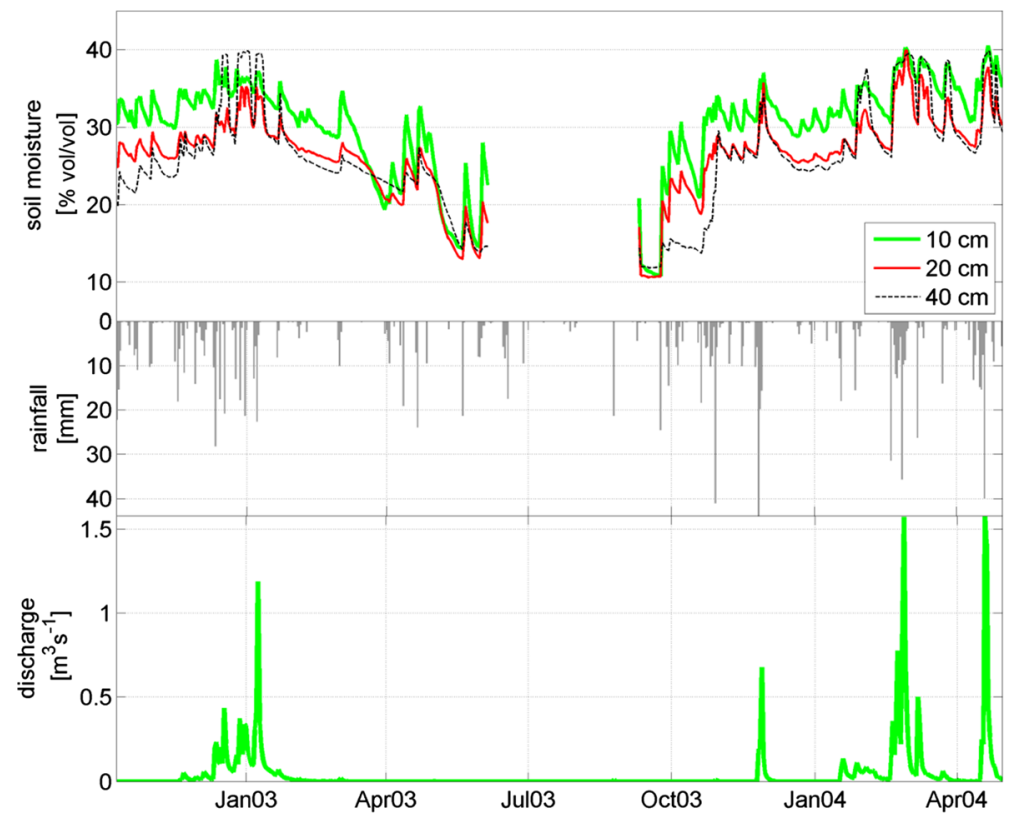

Fig. 2 Temporal variations of soil moisture at three different depths $(10,20$ and $40 \mathrm{~cm})$, daily rainfall and daily discharge in Colorso catchment for the period from October 2002 through to April 2004

(Tayfur et al. 2003), dispersion coefficient prediction (Tayfur 2006), rainfall-runoff modelling (Tayfur and Singh 2006), mean and bankful discharge prediction (Tayfur and Singh 2011), flood control operations (Wang et al. 2011), reservoir operating rule development (Kumar et al. 2013), hydraulic conductivity estimation (Tayfur et al. 2014), among many.

A general fuzzy system has basically four components fuzzification, fuzzy rule base, fuzzy inference engine, and defuzzification (Fig. 3).

\subsection{Fuzzification}

Fuzzification component forms fuzzy sets for input-output variables using membership functions. Fuzzy membership functions may take many forms-trapezoidal, triangular, and bell-shaped (Gaussian). The membership degree varies in between 0 and 1 . The key idea in fuzzy logic is the allowance of partial belongings of any object to different subsets of universal

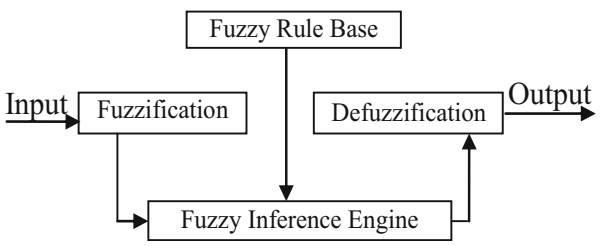

Fig. 3 Schematic representation of Mamdani-type fuzzy system 

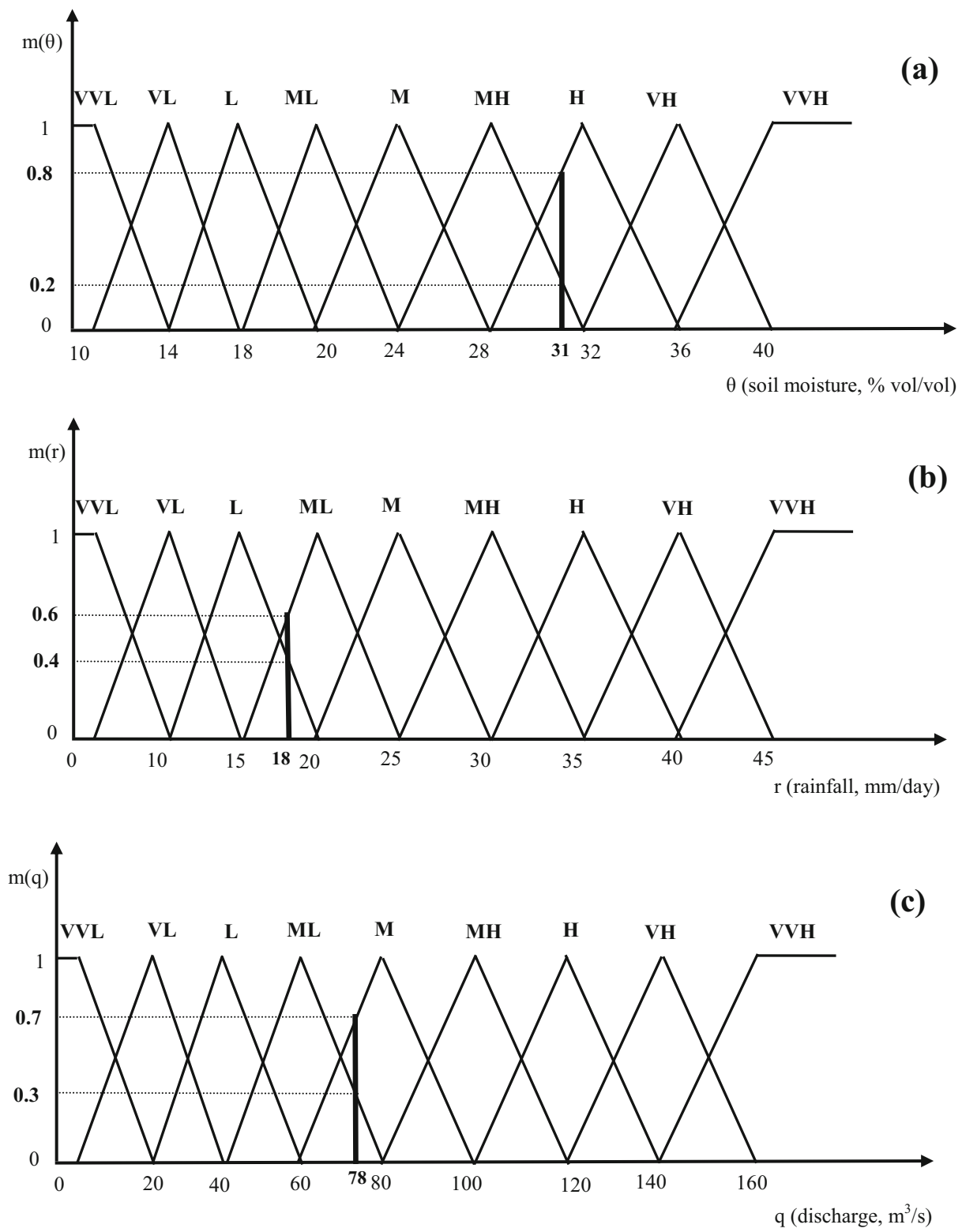

Fig. 4 Fuzzy subsets for: a soil moisture, b rainfall, and c discharge ( $V$ very, $L$ low, $M$ medium, $H$ high)

set. For example, $31 \%$ vol/vol soil moisture in Fig. 4a (taken from the case study analyzed here, see below) belongs to medium high $(\mathrm{MH})$ and high $(\mathrm{H})$ subsets with 0.2 and 0.8 membership degrees, respectively. Intuition, rank ordering, and inductive reasoning can be, among many, ways to assign membership functions to fuzzy variables. The intuitive approach is rather used commonly because it is simple and derived from the innate intelligence and understanding of human beings (Sen 1998; 2004). 


\subsection{Fuzzy Rule Base}

The fuzzy rule base contains rules that include all possible fuzzy relations between inputs and outputs. These rules are expressed in the IF-THEN format. In Mamdani rule system both antecedent and consequent parts of a rule contains verbal statements (Mamdani 1977). The following is an example for a Mamdani rule:

\section{IF soil moisture is low and rainfall is low THEN discharge is very low}

Mamdani rules can be intuitively produced or they can also be constructed from available data and expert view (Sen 2004; Casper et al. 2007; Tayfur 2012). For example; according to Fig. 4, $31 \% \mathrm{vol} / \mathrm{vol}$ soil moisture is a member of $\mathrm{MH}$ and $\mathrm{H}$ subsets with 0.2 and $0.8^{\circ}$ of membership, respectively; $18 \mathrm{~mm} /$ day rainfall is a member of low (L) and medium low (ML) subsets with 0.4 and $0.6^{\circ}$ of memberships, respectively; and $78 \mathrm{~m}^{3} \mathrm{~s}^{-1}$ discharge is a member of $\mathrm{ML}$ and medium (M) with 0.3 and $0.7^{\circ}$ of memberships, respectively. Hence, an observed set of soil moisture of $31 \% \mathrm{vol} / \mathrm{vol}$, rainfall of $18 \mathrm{~mm} /$ day and discharge of $78 \mathrm{~m}^{3} \mathrm{~s}^{-1}$ would yield the following rule, always considering the sets where the variable has the maximum degree of membership (Sen 2004; Tayfur 2012):

\section{IF soil moisture is high and rainfall is medium low THEN discharge is medium}

If the generated rule is not already in the rule base then it is added to the base. Note that, according to the fuzzification of the input variables, the possible number of rules can be $9 \times 9=81$ in order to cover every possible system state. However, working with 81 rules may be cumbersome and furthermore not be suitable from practical point of view. Therefore; the rules whose firing strengths are less than $10 \%$ (or $5 \%$ ) can be eliminated (Coppala et al. 2002). The firing strength of a rule can be simply found by the product of the membership degrees (Coppala et al. 2002; Tayfur 2012). The firing strength of the above rule is $0.8 \times 0.6 \times 0.7=0.34$. Furthermore, the rules which are not physically sound cannot be conserved in the rule base. For example; when soil moisture content is low and rainfall is low, then runoff cannot be high.

\subsection{Fuzzy Inference Engine}

The fuzzy inference engine takes into account all the fuzzy rules in the fuzzy rule base and learns how to transform a set of inputs to corresponding outputs, using min activation operator. In order to illustrate, in a simple manner, the inferencing methodology, the case presented in Fig. 5 is considered. For this simple system, the following fuzzy rules are assumed:

IF $\mathrm{X}$ is low and $\mathrm{Y}$ is low THEN $\mathrm{Z}$ is high

IF $\mathrm{X}$ is high and $\mathrm{Y}$ is high THEN $\mathrm{Z}$ is low

As seen in Fig. 5a, $X=20$ is a part of 'low' and 'high' subsets with membership degrees of 0.8 and 0.2 , respectively. Similarly, $Y=30$ is part of 'low' and 'high' subsets with 0.4 and $0.6^{\circ}$ of membership, respectively (Fig. 5b). When this input pair is fed into fuzzy model, the inference engine would trigger the above rules. From the triggered first and second rules, the engine would find, by min operation, fuzzy output subsets of 'high' and 'low', respectively, with different membership degrees. The obtained subsets are schematically presented, as shaded areas, in Fig. 5c. 

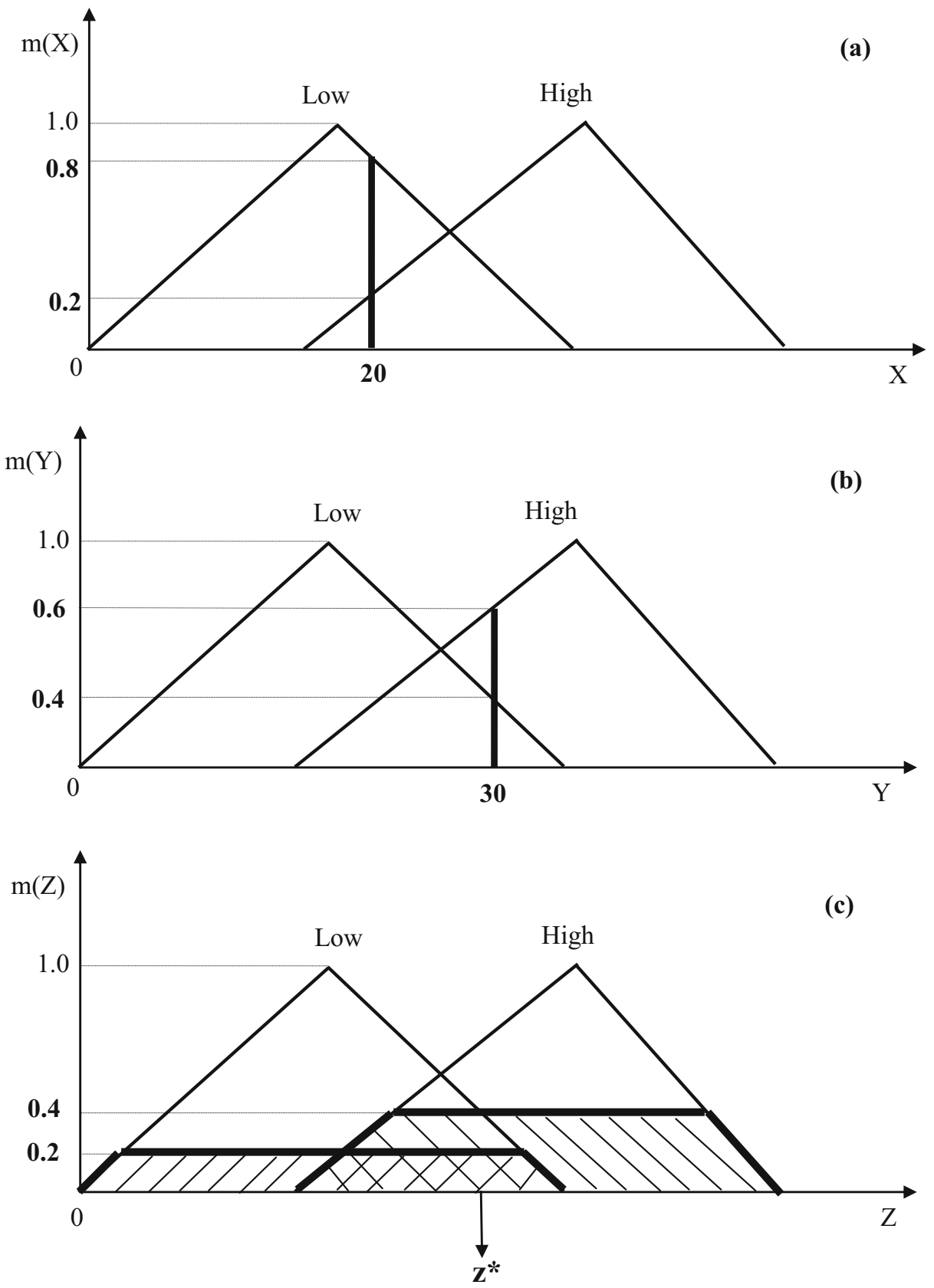

Fig. 5 Schematic representation of fuzzy inferencing: a $X=20$; b $Y=30$; and c fuzzy output sets for $Z$

According to Fig. 5c, the triggered first rule results in 'high' subset with 0.4 membership degree by $\min$ activation (i.e., $\min (\mathbf{0 . 8}, \mathbf{0 . 4})=\mathbf{0 . 4}$, see Fig. $5 \mathrm{c}$, the shaded right trapezoid). The triggered second rule would produce 'low' subset with 
0.2 membership degree (i.e., min $(0.2,0.6)=0.2$, see Fig. $5 c$, the shaded left trapezoid). Note that inferencing produces not a crisp output value but assigns whole fuzzy output subsets from each triggered rule to the output variable, like the two shaded areas in Fig. 5c.

The next sub-process in the inferencing engine is the composition where all of the fuzzy output subsets, obtained as a result of the activation operators from the triggered rules, are combined to form a single fuzzy subset for the output variable. For this purpose, this study employed max composition, where the combined output fuzzy subset is constructed by taking the point-wise maximum over all of the fuzzy output subsets. The details of the inferencing sub-processes are given elsewhere (Sen 2004; Tayfur 2012).

\subsection{Defuzzification}

Defuzzification converts the resulting fuzzy outputs from the fuzzy inference engine to a number. The Center Of Gravity (COG) method (also known as the centroid method) is employed in this study. The crisp output value is the abscissa under the centre of gravity of the combined fuzzy output subset ( $z^{*}$ in Fig. $5 \mathrm{c}$ is assumed to be the centroid of the area and be the crisp value). The centroid method is the most commonly used defuzzification method and for a discrete case it can be expressed as (Jantzen 1999):

$$
z^{*}=\frac{\sum_{i} m\left(z_{i}\right) z_{i}}{\sum_{i} m\left(z_{i}\right)}
$$

where $z^{*}$ is defuzzified output value, $z_{i}$ is output value in the $i^{\text {th }}$ subset, and $m\left(z_{i}\right)$ is membership value of the output value in the $i^{\text {th }}$ subset. For the continuous case, the summations in Eq. (1) are replaced by the integrals. The details of fuzzy logic are available in the literature (Sen 1998; Jantzen 1999; Tayfur 2012).

\section{A Conceptual Rainfall-Runoff Misdc Model}

To assess the performance the fuzzy model with respect to classical continuous rainfall-runoff models, the MISDc ("Modello Idrologico Semi Distribuito in continuo"), developed by Brocca et al. (2011) and already applied successfully by Camici et al. (2011), was employed in this study.

MISDc consists of two main components: 1) a soil water balance (SWB) model to simulate the soil moisture temporal pattern and 2) a semi-distributed event-based Rainfall-Runoff (RR) model (MISD) for flood simulation.

\subsection{Soil Water Balance (SWB) Model}

SWB component of the model assumes that the surface soil layer is spatially lumped system for which the following water content balance equation holds:

$$
\begin{cases}d W(t) / d t=f(t)-e(t)-g(t) & W(t) \leq W_{\max } \\ W(t)=W_{\max } & \text { otherwise }\end{cases}
$$


where $t$ is time, $W(t)$ is the amount of water in the investigated soil layer, $f(t)$ is the infiltration rate, $e(t)$ is the evapotranspiration rate, $g(t)$ is the drainage rate due to the interflow and/or the deep percolation, and $W_{\max }$ is the maximum water capacity of the soil layer. The infiltration rate is estimated by using the Green-Ampt model (Mein and Larson 1973; Tayfur et al. 1993), the drainage and the evapontranspiration rates are estimated following Famiglietti and Wood (1994) and Doorenbos and Pruitt (1977), respectively.

The SWB model requires, as input data, the measured meteorological variables (rainfall and air temperature) and the estimation of five parameters ( $W_{\max }$ : maximum water capacity; $K_{s}$ : saturated hydraulic conductivity; $\psi / L$ : wetting front of soil suction head/ thickness of soil layer; $\lambda$ : pore size distribution index linked to the structure of the soil layer; and $b$ : a parameter). The output of the model is the degree of saturation, $W(t) / W_{\max }$, which is used to determine the initial conditions in MISD.

\subsection{Semi-Distributed Event-Based Rainfall-Runoff Model (MISD)}

MISD model employs the Soil Conservation Service-Curve Number (SCS-CN) method for abstraction for estimation of losses, the geomorphological Instantaneous Unit Hydrograph (IUH) and the linear reservoir IUH for routing of rainfall excess of subcatchments and of areas draining directly into the main channel, respectively. Finally, the routing along the main channel is executed through a diffusive linear approach.

The model, on the basis of the drainage network, and geomorphological and soil/land use characteristics, divides a given catchment into $N_{b}$ elements, each one representing either a subcatchment with outlet along the main channel or an area draining directly into the main channel. It assumes that each element is homogeneous and hence constitutes a lumped system. The rainfall excess, $\varepsilon_{j}(t)$, for an element $j\left(j=1, \ldots, N_{b}\right)$ is given by the well-known SCS-CN formula (Chow et al. 1988):

$$
\begin{cases}\varepsilon_{j}(t)=\frac{\left[r_{j}(t)\left(R_{j}(t)-\lambda_{1} S_{j}\right)\left(R_{j}(t)+\left(2-\lambda_{1}\right) S_{j}\right)\right]}{\left(R_{j}(t)+\left(1-\lambda_{1}\right) S_{j}\right)^{2}} & \\
\varepsilon_{j}(t)=0 & \begin{array}{ll}
R_{j}(t) \geq \lambda_{1} S_{j} \\
\text { otherwise }
\end{array}\end{cases}
$$

where $R_{j}(t)$ is the rainfall depth from the beginning of the storm, $S_{j}$ is the soil potential maximum retention at the beginning of the storm and $\lambda_{l}$ is the parameter linked to the initial abstraction and assumed constant for all elements.

The direct runoff hydrograph, $Y(t)$, at the element outlet is given by the convolution of $\varepsilon(t)$ and the Instantaneous Unit Hydrograph, $h(t)$, as:

$$
Y(t)=A \int_{0}^{t} \varepsilon(\tau) h(t-\tau) d \tau
$$

where $\tau$ is an auxiliary variable for time and $A$ is the element area.

The direct runoff hydrograph, $Q(t)$, at the catchment outlet is estimated by a diffusive linear approach (Troutman and Karlinger 1985):

$$
Q(t)=\sum \int_{0}^{t} Y(\tau) p(t-\tau) d \tau
$$


with $p(t)$ the diffusive routing function given by:

$$
p(t)=\frac{L_{c}}{2\left(\pi D_{j} t^{3}\right)^{1 / 2}} \exp \left(-\frac{\left(c t-L_{c}\right)^{2}}{4 D t}\right)
$$

where $L_{c}$ is the distance between the element and catchment outlet, $c$ is the celerity and $D$ the diffusivity parameter. The model requires, as input data, the rainfall and incorporates three parameters $(\eta, c, D)$.

This study used the lumped version of the model and added a simple component for the simulation of baseflow in order to simulate the discharge also during non-flood conditions, as in Brocca et al. (2013). The full description (details) of the conceptual model is given in Brocca et al. (2011).

\section{Results and Discussion}

The developed Mamdani-type fuzzy model is applied to simulate daily discharge in the period of 2002-2004 for the Colorso basin. Note that the soil moisture at 10, 20, and $40 \mathrm{~cm}$ together with rainfall (see Fig. 2) can form 4 input variables and consequently, by selecting 9 fuzzy subsets for each variable, the possible number of fuzzy rules to be constructed would be $9^{4}=$ 6561. Even by eliminating low firing strength rules and some rules by intuition and expert view, the number of rules in the rule base would still be in the order of hundreds. This would make the model cumbersome and very impractical. Therefore, this study employed two variables and investigated 3 cases. Specifically, rainfall data are used for all cases to which soil moisture data at $10 \mathrm{~cm}$ (case 1), $20 \mathrm{~cm}$ (case 2) and $40 \mathrm{~cm}$ (case 3) is added. Figure 4 presents the constructed fuzzy sets for soil moisture, rainfall, and discharge by taking into account the available data, expert view and intuition. Soil moisture had a range of 10-40\% vol/vol and 9 fuzzy subsets are formed using the commonly employed trapezoidal and triangular membership functions (Fig. 4a). In a similar fashion; 9 fuzzy subsets for rainfall, which had a range of 0-45 mm/day (Fig. 4b), and 9 subsets for discharge [range $0-160 \mathrm{~m}^{3} \mathrm{~s}^{-1}$ ] (Fig. 4c) are formed. Note that in the construction of the fuzzy rules and fuzzy subsets, no calibration procedure is employed. By simply looking at the range and the distribution of soil moisture, rainfall, and runoff data, the fuzzy subsets for each variable were constructed, as shown in Fig. 4. Also, by analysing the relationship between soil moisture, rainfall and discharge in the different seasons, 30 IF-THEN fuzzy rules were optimized that are able to capture all the observed conditions in the investigated basin.

In the case 1, the input variables are soil moisture observed at $10 \mathrm{~cm}$ soil depth and rainfall. Figure 6a presents fuzzy model simulation where although the model captured the highest peaks at the end of the study period, over and under estimations are present at the beginning being the model too sensitive to rainfall inputs. The computed determination coefficient, $\mathbf{R}^{\mathbf{2}}$, and Nash-Sutcliffe efficiency, NS for Fig. 6a are $\mathbf{0 . 4 6}$, and $\mathbf{0 . 4 1}$, respectively. Figure $6 \mathrm{~b}$ presents the simulation for the case 2 (rainfall plus soil moisture at $20 \mathrm{~cm}$ ) where the fuzzy model is found to capture the overall trend but also to underestimate some of the peak values. The performance scores for this case are slightly better, $\boldsymbol{R}^{2}=\mathbf{0 . 6 1}$ and $N \boldsymbol{S}=\mathbf{0 . 5 9}$. The third case, i.e., using soil moisture measured at $40 \mathrm{~cm}$ plus rainfall, shows the best results with $\boldsymbol{R}^{2}=\mathbf{6 9}$ and $\boldsymbol{N S}=\mathbf{0 . 6 8}$. The fuzzy model captures the overall trend but also the peak values satisfactorily both at the beginning and at the end of the study period (see Fig. 6c). The better 


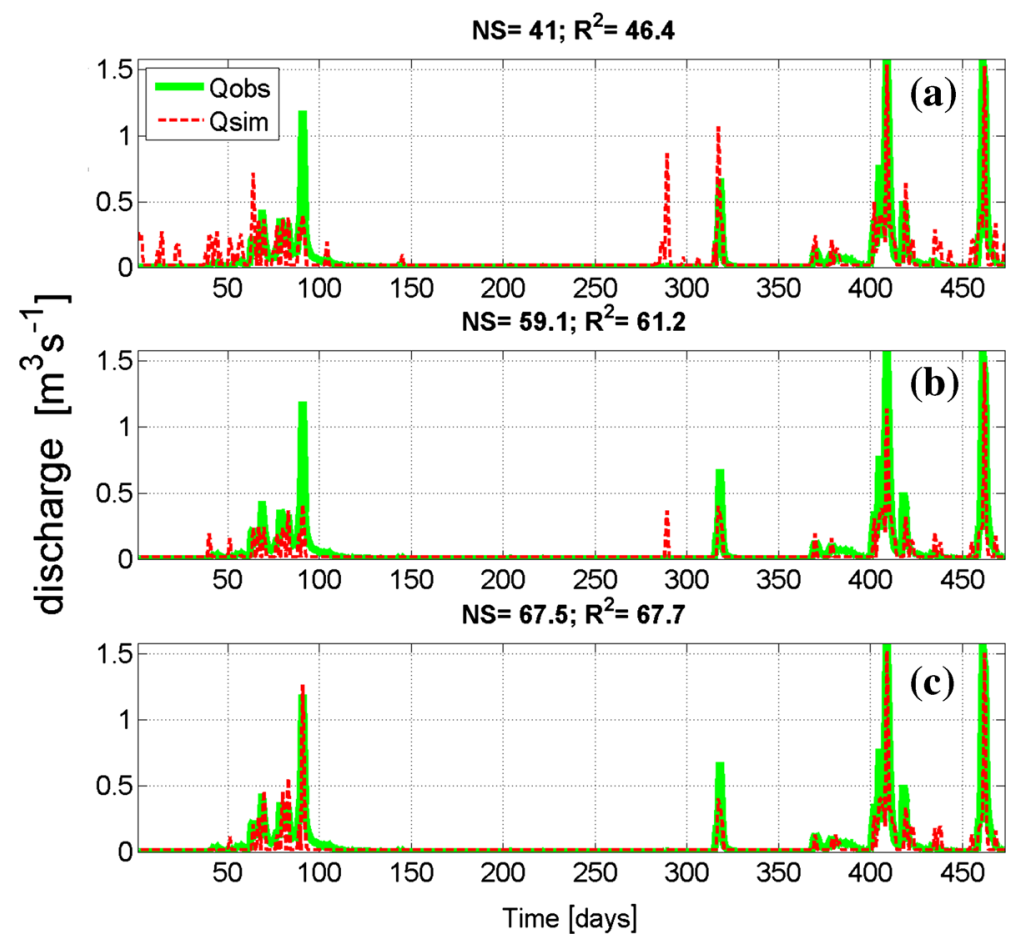

Fig. 6 Rainfall-runoff simulations through the Mamdani-type fuzzy model for the Colorso basin in the period from October 2002 through to April 2004 and for different configurations of the input data, i.e., by using rainfall and soil moisture measured at: a 10 , b 20 , and c $40 \mathrm{~cm}$ (NS Nash-Sutcliffe efficiency index, $R^{2}$ determination coefficient, Qobs and Qsim observed and simulated daily discharge)

results obtained for the soil moisture measurements in the deeper soil layer $(40 \mathrm{~cm})$ well agrees with the expected hydrological behaviour of the investigated catchment for which the rootzone soil layer is the driver of the runoff response instead of surface measurements only.

The performance of the model is also tested against the conceptual rainfall-runoff MISDc model. Specifically, MISDc is calibrated on the same study period (2002-2004) at daily time scale by using continuous rainfall and air temperature data as inputs and by maximizing the NS as objective function. The results of MISDc are shown in Fig. 7 and are compared with both observed discharge and with those simulated by the fuzzy model (case 3). As seen in Fig. 7, the fuzzy model performs better in capturing peak rates and overall trend for high and small flood events. The MISDc model, on the other hand, performs better than fuzzy model in simulating the recession limb of hydrographs, especially in the first period between October 2002 and March 2003. The fuzzy model shows a more flashy response and it is likely due to the form of the fuzzy rules relating the input variables (rainfall and soil moisture) to the output variable (discharge). If the fuzzy rules were refined, it is expected that the fuzzy model would be able to reproduce also the recession limb similarly to the MISDc model. However, the purpose of this study is also to show the simplicity in the building of a fuzzy model only based on an expert view of the relationship between rainfall, soil moisture and discharge, without the need of refining the rules through automatic procedures. Also, it should be noted that the simulation in Fig. 7 by the conceptual model is the calibration run, which is naturally expected to give a better performance. As opposed to the conceptual model, the fuzzy model does not 


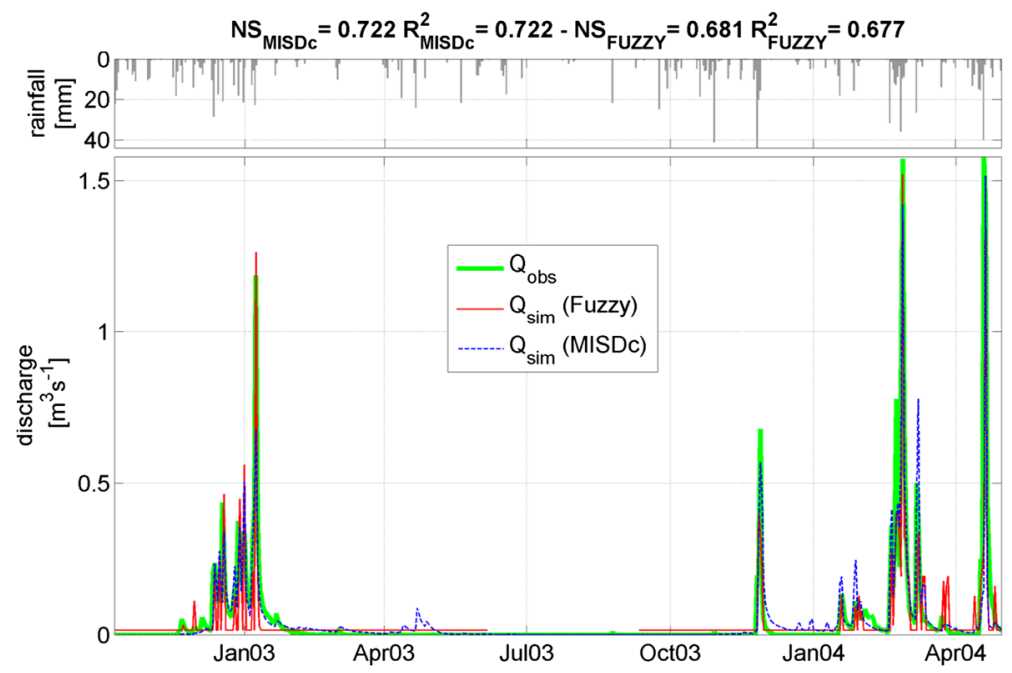

Fig. 7 Comparison between observed, Qobs, and simulated, Qsim, daily discharge for the Colorso basin by using the Mamdani-type fuzzy model (case 3) and the MISDc model (NS Nash-Sutcliffe efficiency index, $R^{2}$ determination coefficient)

require parameter estimation, which is a major problem in hydrological modelling. In MISDc (as in every conceptual rainfall-runoff model), the estimation of 7 model parameter should be carried out and it requires hydrometeorological (input) and discharge (output) measurements for an extended time period ( $>2$ years).

\section{Concluding Remarks}

This study developed Mamdani-type fuzzy logic model to simulate daily discharge as a function of soil moisture and rainfall at $\mathbf{1 3} \mathbf{~ k m}^{\mathbf{2}}$-sized Colorso Basin in central Italy. 9 fuzzy subsets for each variable of soil moisture, rainfall and runoff rate and 30 fuzzy rules are constructed. The fuzzy model employed the min inferencing, max composition and the centroid method.

The model application results reveal that Mamdani-type fuzzy logic model can be employed to incorporate soil moisture along with rainfall to simulate discharge. Soil moisture measured at $40 \mathrm{~cm}$ soil depth along with rainfall produced better results for such a size watershed which is subjected to Mediterranean climate.

Although it uses substantially less data (information) and does not require parameter estimation, the fuzzy model performance is satisfactory when compared to the conceptual MISDc model for which the whole data sets are used for the calibration.

The satisfactory model results obtained in this study also imply that soil moisture measurements in 1 ha area contains useful information that can be scaled up to $13 \mathrm{~km}^{2}$ in accordance with the results shown in Brocca et al. (2009a).

The fuzzy model can be easily constructed solely based upon the expert point of view. It neither necessarily requires the calibration procedure nor brings about the parameter estimation problem. It does not require very precise measurements since it operates with fuzzy sets and can benefit from expert view. 
It should be, however, noted here that the fuzzy model is constructed based upon the range and distribution of the input and output data of the related model variables. Hence, the model cannot be employed for the purpose of extrapolation studies. In other words; if it had to be applied to a different-sized watershed subjected to different climate conditions, the model would need to be reconstructed in the comparably practical way that is presented in this study.

\section{References}

Anctil F, Michel C, Perrin C, Andreassian V (2004) A soil moisture index as an auxiliary ANN input for stream flow forecasting. J Hydrol 286:155-167

Anctil F, Lauzon L, Filion M (2008) Added gains of soil moisture content observations for streamflow predictions using neural networks. J Hydrol 359(3-4):225-234

Aubert D, Loumagne C, Oudin L (2003) Sequential assimilation of soil moisture and streamflow data in a conceptual rainfall runoff model. J Hydrol 280:145-161

Beck HE, de Jeu RAM, Schellekens J, van Dijk AIJM, Bruijnzeel LA (2010) Improving curve number based storm runoff estimates using soil moisture proxies. IEEE J Sel Top Appl Earth Obse Remote Sens 2(4): 1939-1404

Berthet L, Andréassian V, Perrin C, Javelle P (2009) How crucial is it to account for the antecedent moisture conditions in flood forecasting? Comparison of event-based and continuous approaches on 178 catchments. Hydrol Earth Syst Sci 13:819-831

Brocca L, Melone F, Moramarco T, Singh VP (2009a) Assimilation of observed soil moisture data in storm rainfall-runoff modelling. J Hydrol Eng 14(2):153-165

Brocca L, Melone F, Moramarco T, Morbidelli R (2009b) Antecedent wetness conditions estimation based on ERS scatterometer data. J Hydrol 364(1-2):73-87

Brocca L, Melone F, Moramarco T (2011) Distributed rainfall-runoff modelling for flood frequency estimation and flood forecasting. Hydrol Process 25(18):2801-2813

Brocca L, Tullo T, Melone F, Moramarco T, Morbidelli R (2012a) Catchment scale soil moisture spatial-temporal variability. J Hydrol 422-423:63-75

Brocca L, Moramarco T, Melone F, Wagner W, Hasenauer S, Hahn S (2012b) Assimilation of surface and rootzone ASCAT soil moisture products into rainfall-runoff modelling. IEEE Trans Geosci Remote Sens 50(7): 2542-2555

Brocca L, Liersch S, Melone F, Moramarco T, Volk M (2013) Application of a model-based rainfall-runoff database as efficient tool for flood risk management. Hydrol Earth Syst Sci 17:3159-3169

Camici S, Tarpanelli A, Brocca L, Melone F, Moramarco T (2011) Design soil moisture" estimation by comparing continuous and storm-based rainfall-runoff modelling. Water Resour Res 47:W05527

Casper M, Gemmar P, Gronz O, Johst M, Stüber M (2007) Fuzzy logic-based rainfall-runoff modelling using soil moisture measurements to represent system state. Hydrol Sci J 52(3):478-490

Chow VT, Maidment DR, Mays LW (1988) Applied hydrology. McGraw-Hill, New York, Chap. 5.5

Coppala EA, Duckstein L, Davis D (2002) Fuzzy rule based methodology for estimating monthly groundwater rechrage in a temperate watershed. J Hydrol Eng 7(4):326-335

Di Baldassarre G, Montanari A (2010) Uncertainty in river discharge observations: a quantitative analysis. Hydrol Earth Syst Sci 13:913-921

Doorenbos J, Pruitt WO (1977) Background and development of methods to predict reference crop evapotranspiration (ETo). In: FAO-ID-24, Appendix II, 108-119

Elshorbagy A, Corzo G, Srinivasulu S, Solomatine DP (2010) Experimental investigation of the predictive capabilities of data driven modeling techniques in hydrology - part 2: application. Hydrol Earth Syst Sci 14: 1943-1961

Famiglietti JS, Wood EF (1994) Multiscale modeling of spatially variable water and energy balance processes. Water Resour Res 11:3061-3078

Gautam MR, Watanabe K, Saegusa H (2000) Runoff analysis in humid forest catchment with artificial neural network. J Hydrol 235:117-36

Goodrich DC, Schmugge TJ, Jackson TJ, Unkrich CL, Keefer TO, Parry R, Bach LB, Amer SA (2004) Runoff simulation sensitivity to remotely sensed initial soil water content. Water Resour Res 30(5):1393-1406

Grayson RB, Western AW (1998) Towards areal estimation of soil water content from point measurements: time and space stability of mean response. J Hydrol 207:68-82 
Huang M, Gallichand J, Dong C, Wang Z, Shao M (2007) Use of soil moisture data and curve number method for estimating runoff in the Loess Plateau of China. Hydrol Process 21(11):1471-1481

Jacobs JM, Myers DA, Whitfield BM (2003) Improved rainfall/runoff estimates using remotely sensed soil moisture. J Am Water Resour Assoc 4:313-324

Jantzen J (1999) Design of fuzzy controllers. Technical report, No:98-E864, Department of Automation, Technical University of Denmark

Komma J, Blöschl G, Reszler C (2008) Soil moisture updating by Ensemble Kalman filtering in real-time flood forecasting. J Hydrol 357(3-4):228-242

Koren V, Moreda F, Smith M (2008) Use of soil moisture observations to improve parameter consistency in watershed calibration. Phys Chem Earth 33:1068-1080

Kumar ARS, Goyal MK, Ojha CSP, Singh RD, Swamee PK, Nema RK (2013) Application of ANN, fuzzy logic and decision tree algorithms for the development of reservoir operating rules. Water Resour Manag 27(3):911-925

Mamdani EH (1977) Application of the fuzzy logic to approximate reasoning using linguistic synthesis. IEEE Trans Comput C-26:1182-1191

Mein RG, Larson CL (1973) Modeling infiltration during a steady rain. Water Resour Res 9(2):384-394

Merz R, Plate EJ (1997) An analysis of the effects of spatial variability of soil and soil moisture on runoff. Water Resour Res 33(12):2909-2922

Merz R, Bardossy A (1998) Effects of spatial variability on the rainfall runoff process in a small loess catchment. J Hydrol 212-213:304-317

Meyles E, Williams A, Ternan L, Dowd J (2003) Runoff generation in relation to soil moisture patterns in a small Dartmoor catchment, Southwest England. Hydrol Process 17:251-264

Morbidelli R, Corradini C, Saltalippi C, Brocca L (2012) Initial soil water content as input to field-scale infiltration and surface runoff models. Water Resour Manag 26(7):1793-1807

Panigrahi DP, Mujumdar PP (2000) Reservoir operation modelling with fuzzy logic. Water Resour Manag 14(2): 89-109

Parajka J, Naemi V, Bloschl G, Komma J (2009) Matching ERS scatterometer based soil moisture patterns with simulations of a conceptual dual layer hydrologic model over Austria. Hydrol Earth Syst Sci 13:259-271

Scipal K, Drusch M, Wagner W (2008) Assimilation of a ERS scatterometer derived soil moisture index in the ECMWF numerical weather prediction system. Adv Water Resour 31:1101-1112

Sentek Sensor Technologies (1997) Enviroscan: hardware manual, version 3.0. Sentek Pty Ltd, Australia

Sen Z (1998) Fuzzy algorithm for estimation of solar irradiation from sunshine duration. Solar Energy 63(1):39-49

Sen Z (2004) Fuzzy logic and system models in water sciences. Turkish Water Foundation, İstanbul

Tagaki T, Sugeno M (1985) Fuzzy identification of systems and its applications to modelling and control. IEEE Trans Syst Man Cybern 15:116-132

Tayfur G, Kavvas ML, Govindaraju RS, Storm DE (1993) Applicability of St.Venant equations for twodimensional overland flows over rough infiltrating surfaces. J Hydraul Eng 119(1):51-63

Tayfur G, Ozdemir S, Singh VP (2003) Fuzzy logic algorithm for runoff-induced sediment transport from bare soil surfaces. Adv Water Resour 26(12):1249-1256

Tayfur G (2006) Fuzzy, ANN, and regression models to predict longitudinal dispersion coefficient in natural streams. Hydrol Res Nordic Hydrol 37(2):143-164

Tayfur G, Singh VP (2006) ANN and fuzzy logic models for simulating event-based rainfall-runoff. J Hydraul Eng 132(12):1321-1330

Tayfur G, Singh VP (2011) Predicting mean and bankfull discharge from channel cross-sectional area by expert and regression methods. Water Resour Manag 25(5):1253-1267

Tayfur G (2012) Soft computing in water resources engineering. WIT Press, Southampton

Tayfur G, Nadiri AA, Moghaddam AA (2014) Supervised intelligent committee machine method for hydraulic conductivity estimation. Water Resour Manag 28(4):1173-1184

Troutman BM, Karlinger MB (1985) Unit hydrograph approximation assuming linear flow trough topologically random channel networks. Water Resour Res 21:743-754

van Steenbergen N, Willems P (2013) Increasing river flood preparedness by real-time warning based on wetness state conditions. J Hydrol 489:227-237

Wang XJ, Zhao RH, Hao YW (2011) Flood control operations based on the theory of variable fuzzy sets. Water Resour Manag 25(3):777-792

Wooldridge SA, Kalma JD, Walker JP (2003) Importance of soil moisture measurements for inferring parameters in hydrologic models of low-yielding ephemeral catchments. Environ Model Software 18(1):35-48

Zehe E, Graeff T, Morgner M, Bauer A, Bronstert A (2010) Plot and field scale soil moisture dynamics and subsurface wetness control on runoff generation in a headwater in the Ore mountains. Hydrol Earth Syst Sci 14:873-889 